\title{
Efficacy and safety of twice-daily aclidinium bromide in COPD patients: the ATTAIN
} study

\author{
Paul W. Jones*, Dave Singh\#", Eric D. Bateman`, Alvar Agusti ${ }^{+}$, Rosa Lamarca ${ }^{\S}$, \\ Gonzalo de Miquel $^{\S}$, Rosa Segarra ${ }^{\S}$, Cynthia Caracta ${ }^{f}$ and Esther Garcia Gil ${ }^{\S}$
}

ABSTRACT: The efficacy and safety of two doses of aclidinium bromide were evaluated in patients with moderate to severe chronic obstructive pulmonary disease (COPD).

In this 24-week, double-blind trial, patients were randomised to twice-daily aclidinium $(200 \mu \mathrm{g}$ or $400 \mu \mathrm{g})$ or placebo. The primary efficacy end-point was change in trough forced expiratory volume in 1 s (FEV1) at week 24. Other end-points included peak FEV1, health status (St George's Respiratory Questionnaire; SGRQ) and dyspnoea (Transitional Dyspnoea Index; TDI).

Overall, 828 patients were randomised. At week 24, significant improvements from baseline were observed with aclidinium $200 \mu \mathrm{g}$ and $400 \mu \mathrm{g}$ versus placebo for trough FEV 1 (99 and $128 \mathrm{~mL}$; both $\mathrm{p}<0.0001)$ and peak FEV1 (185 and $209 \mathrm{~mL}$; both $\mathrm{p}<\mathbf{0 . 0 0 0 1 )}$. Peak FEV 1 improvements on day 1 were comparable with week 24. Aclidinium $200 \mu \mathrm{g}$ and $400 \mu \mathrm{g}$ produced significant improvements over placebo in baseline-adjusted mean SGRQ total score (-3.8 and -4.6 units; $\mathbf{p}<0.001$ and $\mathbf{p}<0.0001)$ and TDI focal score (0.6 and 1.0 units; $\mathbf{p}<0.05$ and $\mathbf{p}<0.001)$ at week 24 . With both aclidinium doses, the incidence of anticholinergic adverse events was low, and similar to placebo.

Twice-daily aclidinium significantly improved bronchodilation, health status and dyspnoea, and was well tolerated in patients with COPD.

KEYWORDS: Anticholinergic, bronchodilation, dyspnoea, exacerbations, health status, longacting muscarinic antagonist

hronic obstructive pulmonary disease (COPD) is an increasing public health problem that imposes a considerable burden in terms of morbidity, mortality and healthcare costs worldwide [1]. Although not curable, COPD is treatable, with bronchodilator therapy being central to the symptomatic management of the disease [2,3].

Aclidinium bromide, a novel, inhaled long-acting muscarinic antagonist compound with low systemic activity, has been developed for the treatment of COPD. Initially, aclidinium was investigated as a once-daily drug. In phase III studies, once-daily aclidinium $200 \mu \mathrm{g}$ significantly improved trough forced expiratory volume in $1 \mathrm{~s}$ (FEV1) in patients with COPD versus placebo [4], but this improvement was below the suggested minimum clinically important difference (MCID) of 100-140 mL [5, 6]. Therefore, additional clinical studies were conducted to investigate twice-daily aclidinium. A 2week crossover study showed that aclidinium $400 \mu$ b.i.d. provided 24-h bronchodilation that was statistically and clinically significant compared with placebo [7]. Subsequently, a 12-week phase III study (AClidinium in Chronic Obstructive Respiratory Disease; ACCORD COPD I) with aclidinium $200 \mu \mathrm{g}$ and $400 \mu \mathrm{g}$ b.i.d. reported significant improvements over placebo in bronchodilation, health status and COPD symptoms [8].

This paper presents results from a phase III study of longer duration (Aclidinium To Treat Airway obstruction In COPD patieNts; ATTAIN), which assessed the efficacy and safety of aclidinium $200 \mu \mathrm{g}$ and $400 \mu \mathrm{g}$ b.i.d. versus placebo over 24 weeks in patients with moderate to severe COPD.

\section{METHODS}

\section{Study subjects}

Male and female patients aged $\geqslant 40$ yrs were included if they were current or former cigarette smokers with a smoking history of $\geqslant 10$ pack-yrs and had a diagnosis of COPD according to Global Initiative for Chronic Obstructive Lung Disease criteria (post-bronchodilator FEV1/forced vital
AFFILIATIONS

*St George's, University of London, London, and

\#University of Manchester, Medicines Evaluation Unit Ltd, Manchester, UK.

-University of Cape Town, Cape Town, South Africa. +Thorax Institute, Hospital Clínic, University of Barcelona, and Fundación Investigación Sanitaria Illes Balears (FISIB), Centro de Investigación Biomédica en Red Enfermedades Respiratorias (CIBERES), Mallorca, and ${ }^{5}$ Almirall SA, Barcelona, Spain. ${ }^{f}$ Forest Research Institute, Jersey City, NJ, USA.

CORRESPONDENCE

P.W. Jones

St George's

University of London

Cranmer Terrace

London

SW17 ORE

UK

E-mail: pjones@sgul.ac.uk

Received:

Dec 232011

Accepted after revision:

March 052012

First published online:

March 222012

European Respiratory Journal

Print ISSN 0903-1936

Online ISSN 1399-3003 
capacity (FVC) ratio of $<70 \%$ and $\mathrm{FEV} 1<80 \%$ of the predicted value) [2]. Patients had to demonstrate good technique during lung function assessments according to American Thoracic Society/European Respiratory Society criteria [9].

Key exclusion criteria were: history or current diagnosis of asthma; respiratory tract infection or COPD exacerbation within 6 weeks (3 months if hospitalisation was required) before screening or during the run-in period; clinically relevant respiratory conditions other than COPD; unstable cardiac conditions, including myocardial infarction, within the previous 6 months; and contraindications to the use of anticholinergic drugs.

Inhaled salbutamol was permitted as needed, but was discontinued $6 \mathrm{~h}$ before and during study visits. The following concomitant medications were allowed if their administration had been stable for $\geqslant 4$ weeks before screening: inhaled corticosteroids or oral sustained-release theophyllines; systemic corticosteroids at doses equivalent to $10 \mathrm{mg}$ per day of prednisone or $20 \mathrm{mg}$ every other day; and oxygen therapy ( $<15 \mathrm{~h}$ per day).

This study was conducted in accordance with the Declaration of Helsinki, International Conference on Harmonisation/Good Clinical Practice Guidelines and local regulations. The protocol was approved by an independent ethics committee at each centre before study initiation. All patients gave written informed consent. The study was registered with ClinicalTrials.gov with identifier NCT01001494.

\section{Study design}

This was a double-blind, randomised, placebo-controlled, parallel-group phase III study conducted in nine European countries and South Africa. Following screening and a 2-week run-in period to assess disease stability, patients were randomised (1:1:1) to receive aclidinium $200 \mu \mathrm{g}$, aclidinium $400 \mu \mathrm{g}$ or placebo b.i.d. for 24 weeks. All study treatments were administered via a multiple-dose dry powder inhaler (Genuair ${ }^{\circledR}$; Almirall SA, Barcelona, Spain).

A sample size of 244 patients per treatment arm was estimated to provide at least $90 \%$ power to detect a difference of $90 \mathrm{~mL}$ in trough FEV1 between the aclidinium arms and placebo at week 24 with a two-sided $5 \%$ level of significance, assuming a standard deviation of $240 \mathrm{~mL}$ and adjusting for multiple treatment comparisons. The sample size provided sufficient power to detect treatment differences in the secondary end-points.

\section{Measurements}

Standardised spirometric measurements (FEV1, FVC and inspiratory capacity) [9] were conducted before the morning dose on day 1 (baseline) and during visits at weeks 1, 4, 8, 12, 18 and 24 . Additionally, FEV1 and FVC measurements were obtained at 0.5, 1,2 and $3 \mathrm{~h}$ post-dose and inspiratory capacity measurements at $3 \mathrm{~h}$ post-dose on day 1 and weeks 1, 4, 12 and 24. Inspiratory capacity was measured using an inspiratory manoeuvre to total lung capacity from stable tidal breathing [9]. All study centres had identical spirometry equipment, a detailed study manual and training. Spirometry data were electronically transmitted to a data management centre for quality review and only technically adequate measurements were accepted.

Health status was evaluated pre-dose at baseline and weeks 4, 12 and 24 using the St George's Respiratory Questionnaire
(SGRQ). Dyspnoea was assessed at baseline using the Baseline Dyspnoea Index (BDI) and changes were measured using the Transitional Dyspnoea Index (TDI) at weeks 4, 12 and 24. The BDI and TDI were administered by an independent reviewer before study procedures.

Patients recorded COPD symptoms and relief medication use daily in an electronic diary; concomitant medications were recorded by the patient in a paper diary. At each visit, COPD exacerbations were identified by the investigator by reviewing records of COPD symptoms, use of daily relief medication and concomitant medications. COPD exacerbations were defined as an increase in COPD symptoms over at least 2 consecutive days, resulting in the increased use of short-acting bronchodilators and/or inhaled corticosteroids (mild exacerbation), treatment with antibiotics and/or systemic corticosteroids (moderate exacerbation), or hospitalisation (severe exacerbation).

Safety was assessed by adverse event monitoring, clinical laboratory data, blood pressure and 12-lead ECG.

\section{Statistical analysis}

The primary efficacy end-point was the change from baseline in morning pre-dose (trough) FEV1 at week 24. Secondary endpoints were the change from baseline in peak FEV1 (highest FEV1 value observed within $3 \mathrm{~h}$ of morning dosing) at week 24 and the percentages of patients achieving clinically significant improvements in SGRQ total score and TDI focal score at week 24. For US regulatory requirements, trough and peak FEV1 values at week 12 were also assessed as primary and secondary end-points, respectively.

Efficacy analyses were performed on the intent-to-treat (ITT) population, defined as all patients who took one or more dose of study medication and had a baseline and one or more postbaseline FEV1 assessment. Missing data were imputed using last observation carried forward (LOCF). For spirometry data, linear interpolation and time-matched LOCF were applied. Changes from baseline in lung function parameters and SGRQ and TDI scores were evaluated using ANCOVA, with treatment group and sex as factors, and age and baseline value as covariates. The percentages of patients with clinically significant improvements in SGRQ (decrease of $\geqslant 4$ units [10]) and TDI (increase of $\geqslant 1$ unit [11]) scores were analysed using logistic regression with treatment group, sex, age and baseline value as covariates. Use of relief medication was analysed using normal scores ANCOVA, with treatment group and sex as factors, and age and corresponding normal score baseline as covariates. An annualised rate of COPD exacerbations was calculated using Poisson regression with correction for over-dispersion with treatment group, sex and baseline COPD severity as factors, and age as a covariate. Logistic regression, including treatment group and baseline COPD severity as covariates, was used to analyse the percentage of patients with one or more COPD exacerbation. Safety outcomes were analysed descriptively for the safety population, defined as patients who received one or more dose of study medication.

\section{RESULTS}

\section{Patient characteristics}

Of the 828 randomised patients, 819 patients were included in the ITT and safety populations. Figure 1 shows patient disposition. 


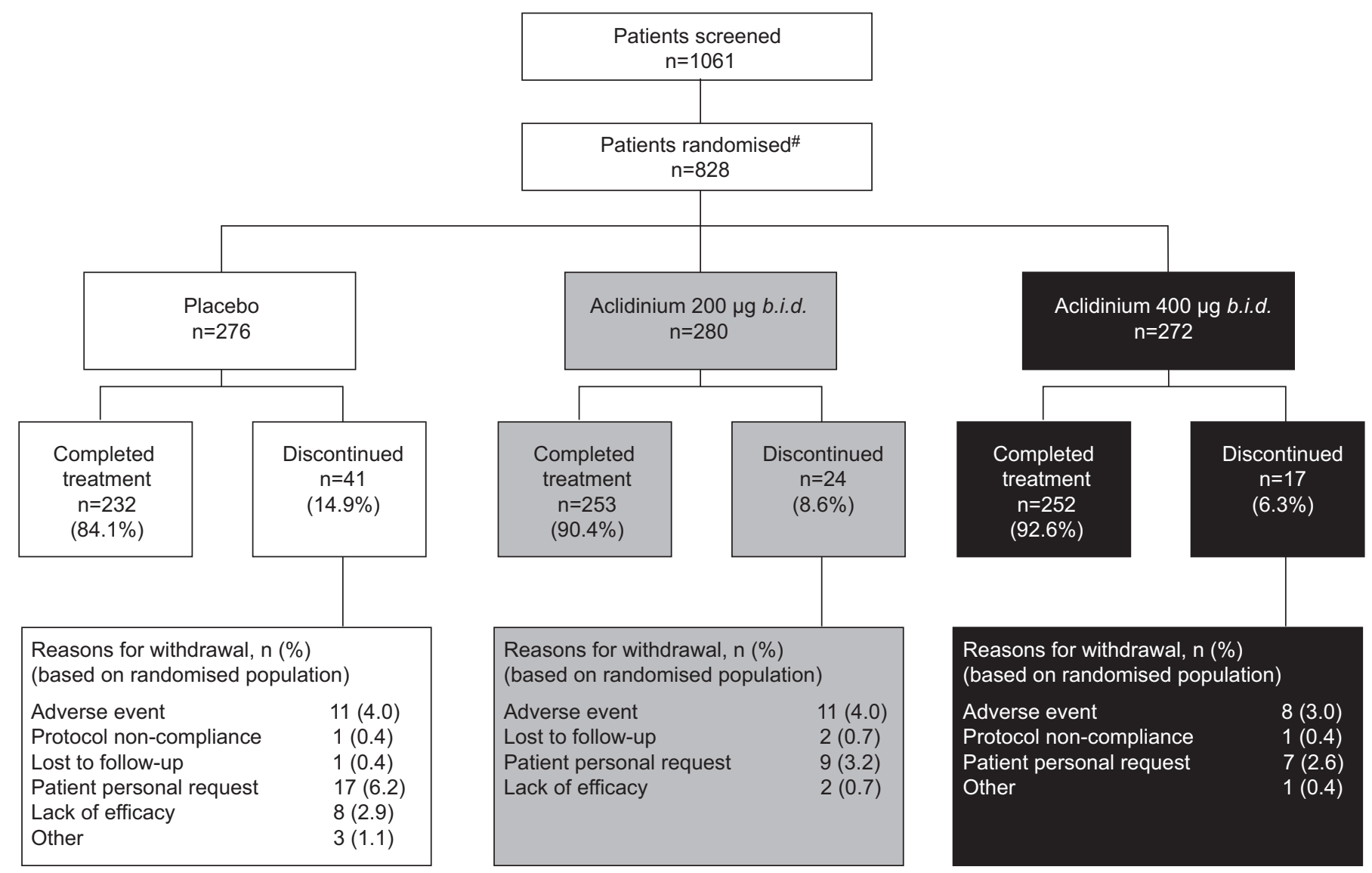

FIGURE 1. Patient disposition. ${ }^{\#}$ : nine patients from one centre were counted as randomised only due to missing baseline data; therefore, the numbers of patients who completed or discontinued treatment do not add up to the total number randomised.

Baseline demographics and disease status were similar across treatment groups (table 1).

\section{Efficacy}

\section{Lung function}

At week 24, aclidinium $200 \mu \mathrm{g}$ and $400 \mu \mathrm{g}$ produced significant improvements from baseline in mean \pm SE trough FEV1 compared with placebo (by $99 \pm 22 \mathrm{~mL}$ and $128 \pm 22 \mathrm{~mL}$, respectively; $\mathrm{p}<0.0001$ for both) (fig. 2). For both aclidinium doses, the improvement in trough FEV1 was statistically superior to placebo at all measured time points from week 1 to week 24, ranging from $77 \mathrm{~mL}$ (week 12) to $105 \mathrm{~mL}$ (week 18) for aclidinium $200 \mu \mathrm{g}$, and from $105 \mathrm{~mL}$ (week 12) to $140 \mathrm{~mL}$ (week 18) for aclidinium $400 \mu \mathrm{g}$ (fig. 2; table 2).

Mean \pm SE peak FEV1 significantly improved from baseline with aclidinium $200 \mu \mathrm{g}$ and $400 \mu \mathrm{g}$ versus placebo at week 24 (by $185 \pm 23 \mathrm{~mL}$ and $209 \pm 24 \mathrm{~mL}$, respectively; $\mathrm{p}<0.0001$ for both) (fig. 3). At week 12, the corresponding improvements were $182 \pm 21 \mathrm{~mL}$ and $191 \pm 21 \mathrm{~mL}$, respectively ( $\mathrm{p}<0.0001$ for both). The improvement in peak FEV1 provided by both aclidinium doses was statistically superior to placebo at all time points from day 1 to week 24 (fig. 3 and table 2). Following the first dose of aclidinium, the increase in peak FEV1 over placebo on day 1 (187 mL, $400 \mu \mathrm{g}$ ) was comparable to that seen at study end $(209 \mathrm{~mL}, 400 \mu \mathrm{g})$. The mean post-dose time to peak FEV1 was
$<2 \mathrm{~h}$ for aclidinium $200 \mu \mathrm{g}$ and $400 \mu \mathrm{g}$ at all time points except for day 1 (127 and $126 \mathrm{~min}$, respectively).

Both aclidinium doses resulted in significant improvements over placebo in FVC and inspiratory capacity values throughout the study (table 2). Numerically greater improvements in trough FVC and trough inspiratory capacity were observed with the $400 \mu \mathrm{g}$ versus $200 \mu \mathrm{g}$ dose at all time points; these improvements were statistically significant $(\mathrm{p}<0.05)$ at weeks $1,8,12$ and 18 for trough FVC and at weeks 1,12 and 18 for trough inspiratory capacity. Aclidinium $400 \mu \mathrm{g}$ also produced numerically greater improvements versus aclidinium $200 \mu \mathrm{g}$ in peak FVC at all time points except week 12; these improvements were statistically significant $(\mathrm{p}<0.05)$ at weeks 1 and 24 .

\section{Health status}

Significantly greater improvements from baseline in mean SGRQ total score were observed with both aclidinium doses versus placebo at all time points, except week 4 with aclidinium $200 \mu \mathrm{g}$ (fig. 4). By week 24, the improvement over placebo in baseline-adjusted mean \pm SE SGRQ total score was $-3.8 \pm 1.1$ units for aclidinium $200 \mu \mathrm{g}(\mathrm{p}<0.001)$ and $-4.6 \pm 1.1$ units for aclidinium $400 \mu \mathrm{g}(\mathrm{p}<0.0001)$. More patients had a clinically significant improvement in SGRQ total score ( $\geqslant 4$ units) at week 24 with aclidinium $200 \mu \mathrm{g}$ and $400 \mu \mathrm{g}$ compared with placebo $(56.0 \%$ and $57.3 \%$ versus $41.0 \%$; odds ratio 1.83 and 1.87; $\mathrm{p}<0.001$ for both). 
TABLE 1 Baseline demographics and disease status

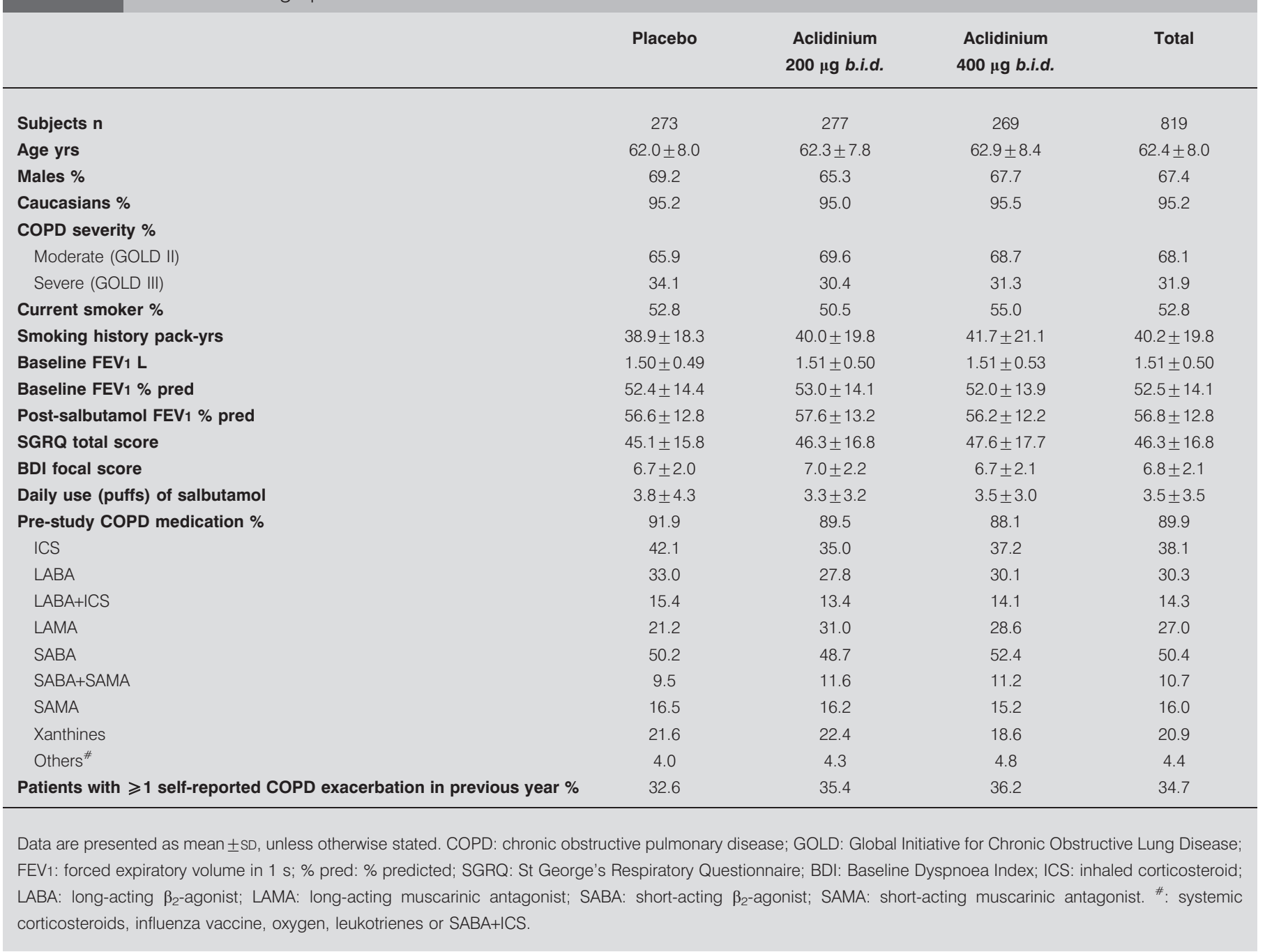

\section{Dyspnoea and relief medication use}

Both aclidinium doses provided significantly greater improvements from baseline in TDI focal score compared with placebo

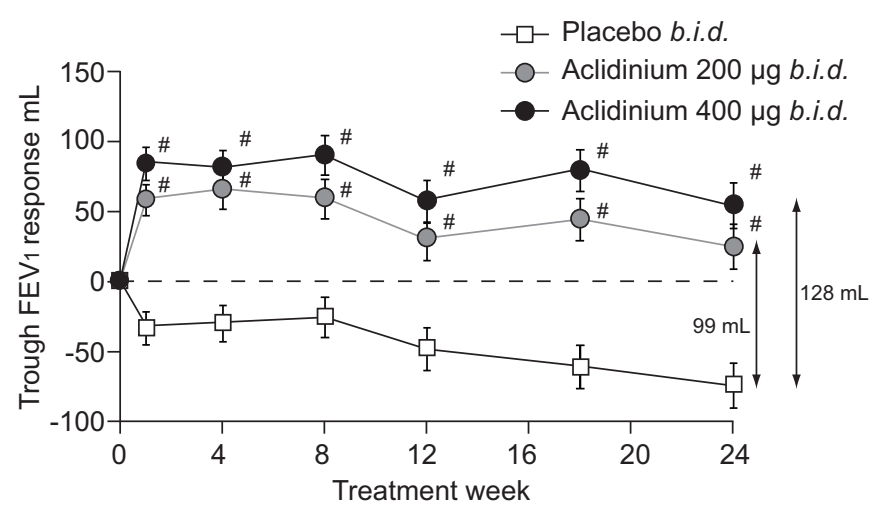

FIGURE 2. Change from baseline in trough forced expiratory volume in $1 \mathrm{~s}$ (FEV1) over 24 weeks. Data are presented as least squares mean \pm SE. ${ }^{*}$ : $p<0.0001$ for both treatments versus placebo. There were no statistically significant differences between the two aclidinium arms. at all time points, except week 12 for aclidinium $200 \mu \mathrm{g}$ (fig. 5). The improvement over placebo in baseline-adjusted mean \pm SE TDI focal score at week 24 was $0.6 \pm 0.3$ units for aclidinium $200 \mu \mathrm{g} \quad(\mathrm{p}<0.05)$ and $1.0 \pm 0.3$ unit for aclidinium $400 \mu \mathrm{g}$ $(p<0.001)$. More patients treated with aclidinium $200 \mu \mathrm{g}$ and $400 \mu \mathrm{g}$ had a clinically significant improvement in TDI focal score ( $\geqslant 1$ unit) at week 24 compared with placebo (53.3\% and $56.9 \%$ versus $45.5 \%$; odds ratio 1.47 and $1.68 ; \mathrm{p}<0.05$ and $\mathrm{p}<0.01$, respectively).

Over 24 weeks, the mean total daily use of relief medication was significantly reduced from baseline with aclidinium $200 \mu \mathrm{g}$ (by 0.61 puffs per day; $\mathrm{p}=0.0002$ ) and aclidinium $400 \mu \mathrm{g}$ (by 0.95 puffs per day; $p<0.0001)$ compared with placebo. The percentage of days without the need for relief medication over 24 weeks was significantly increased over placebo by $11 \%$ for both doses of aclidinium $(\mathrm{p}<0.001$ for both).

\section{COPD exacerbations}

The rate of exacerbations of any severity was lower with aclidinium $200 \mu \mathrm{g}$ and $400 \mu \mathrm{g}$ versus placebo (0.43 and 0.40 versus 0.60 per patient per year, respectively). Compared with placebo, the rate ratio with aclidinium $200 \mu \mathrm{g}$ was 0.72 (95\% CI 


\begin{tabular}{lcc}
\hline TABLE 2 & $\begin{array}{l}\text { Baseline-adjusted mean differences between } \\
\text { aclidinium and placebo in lung function } \\
\text { parameters at all time points over } 24 \text { weeks }\end{array}$ \\
\hline Parameter & Aclidinium $\mathbf{2 0 0} \boldsymbol{\mu g}$ b.i.d. & Aclidinium $\mathbf{4 0 0} \boldsymbol{\mu g}$ b.i.d. \\
\hline Trough FEV $\mathbf{~ m L}$ & $77-105^{\circ}$ & $105-140^{+}$ \\
Peak FEV $\mathbf{~ m L}$ & $161-185^{+}$ & $187-211^{+}$ \\
Trough FVC $\mathbf{~ m L}$ & $119-159^{\#}$ & $184-224^{+}$ \\
Peak FVC $\mathbf{~ m L}$ & $242-276^{+}$ & $257-295^{+}$ \\
Trough IC $\mathbf{~ m L}$ & $57-70^{*}$ & $109-133^{+}$ \\
\hline
\end{tabular}

Data are reported as the minimum and maximum values over the treatment period. FEV1: forced expiratory volume in $1 \mathrm{~s}$; FVC: forced vital capacity; IC: inspiratory capacity. ${ }^{*}: p<0.05 ;{ }^{*}: p \leqslant 0.0002 ;{ }^{\top}: p \leqslant 0.0001 ;{ }^{+}: p<0.0001$. The indicated $p$-values apply over the entire range.

0.52-0.99; $\mathrm{p}<0.05)$ and 0.67 (95\% CI 0.48-0.94; $\mathrm{p}<0.05)$ with aclidinium $400 \mu \mathrm{g}$. The frequency of moderate or severe exacerbations was also lower for aclidinium $200 \mu \mathrm{g}$ and $400 \mu \mathrm{g}$ versus placebo (0.35 and 0.34 versus 0.47 per patient per year, respectively), but the rate ratios did not reach statistical significance $(0.74,95 \%$ CI $0.53-1.04$ and $0.72,95 \%$ CI $0.51-1.02 ; p=0.08$ and $\mathrm{p}=0.06$, respectively).

\section{Safety}

The percentage of patients with at least one treatment-emergent adverse event was similar for placebo, aclidinium $200 \mu \mathrm{g}$ and aclidinium $400 \mu \mathrm{g}$ (57.1\%, 54.5\% and 53.5\%, respectively). Table 3 shows adverse events reported by $\geqslant 2 \%$ of patients in any treatment group.

Potential anticholinergic adverse events occurred with an incidence of $<1 \%$ in any treatment group and were reported at a similar or lower incidence in the aclidinium $200 \mu \mathrm{g}$ and $400 \mu \mathrm{g}$ groups compared with placebo, except for urinary tract infection $(0.7 \%, 2.2 \%$ and $0.7 \%$, respectively). The percentage of patients reporting dry mouth was low and similar in each group (placebo: 0.4\%; aclidinium $200 \mu \mathrm{g}$ : 0.7\%; aclidinium $400 \mu \mathrm{g}$ : 0.4\%).

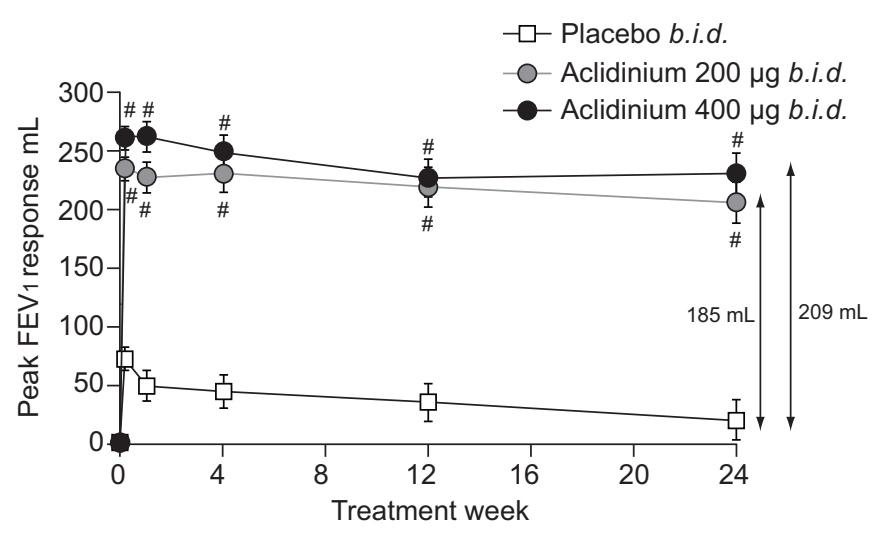

FIGURE 3. Change from baseline in peak forced expiratory volume in $1 \mathrm{~s}$ (FEV1) over 24 weeks. Data are presented as least squares mean \pm SE. ${ }^{*}: p<0.0001$ for both treatments versus placebo. There were no statistically significant differences between the two aclidinium arms.

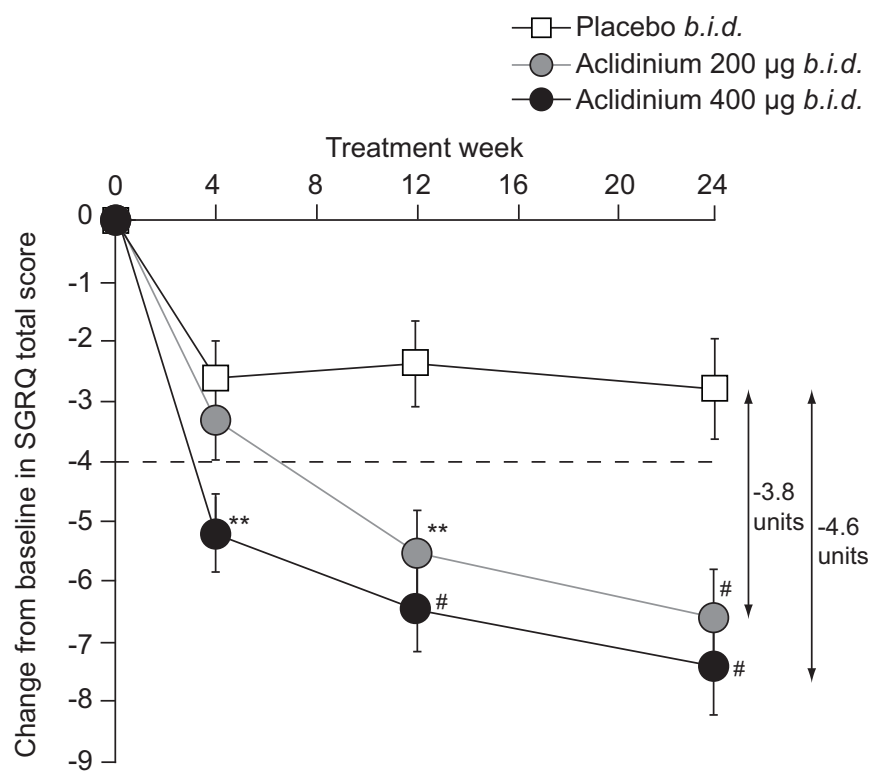

FIGURE 4. Change from baseline in St George's Respiratory Questionnaire (SGRQ) total score over 24 weeks. Data are presented as least squares mean \pm SE. Values on or below the dotted line represent clinically significant improvement. **: $p<0.01 ;{ }^{*}: p<0.0001$ versus placebo.

The percentage of patients experiencing a serious adverse event was similar across the three groups (placebo: $5.5 \%$; aclidinium $200 \mu \mathrm{g}$ : 4.3\%; aclidinium $400 \mu \mathrm{g}$ : 5.6\%). The most common serious adverse event by preferred term was COPD exacerbation, which was reported by $3.7 \%, 1.4 \%$ and $0.7 \%$ of patients in the placebo, aclidinium $200 \mu \mathrm{g}$ and aclidinium $400 \mu \mathrm{g}$ groups, respectively. Other preferred terms were reported as serious adverse events by no more than one patient in any treatment group. No serious adverse events were considered by the local investigator to be related to study medication. Three patients died during the study; one each in the placebo (road traffic accident), aclidinium $200 \mu \mathrm{g}$ (myocardial infarction) and aclidinium $400 \mu \mathrm{g}$ (acute cardiac failure) groups. None of the deaths was thought to be related to treatment.

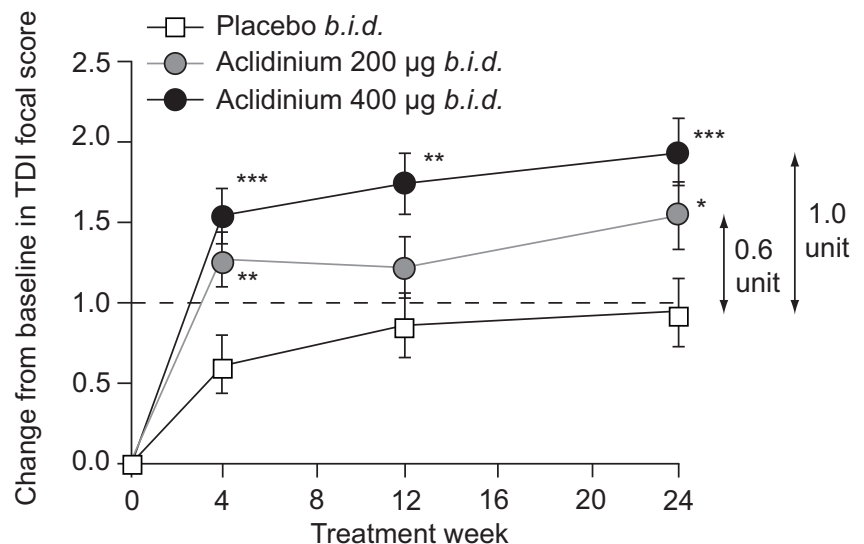

FIGURE 5. Change from baseline in Transitional Dyspnoea Index (TDI) focal score over 24 weeks. Data are presented as least squares mean \pm SE. Values on or above the dotted line represent clinically significant improvement. *: $p<0.05$; $\star *: p<0.01 ; * * *: p<0.001$ versus placebo. 
TABLE 3 Adverse events reported by $\geqslant 2 \%$ of patients in any treatment group (safety population)

\begin{tabular}{|c|c|c|c|}
\hline \multirow[t]{2}{*}{ Preferred term } & \multicolumn{3}{|c|}{ Patients } \\
\hline & Placebo" & Aclidinium $200 \mu$ g b.i.d. ${ }^{\top}$ & Aclidinium $400 \mu \mathrm{g}$ b.i.d. ${ }^{+}$ \\
\hline COPD exacerbations & $56(20.5)$ & $44(15.9)$ & $38(14.1)$ \\
\hline Headache & $22(8.1)$ & $30(10.8)$ & 33 (12.3) \\
\hline Nasopharyngitis & $23(8.4)$ & $32(11.6)$ & $30(11.2)$ \\
\hline Bronchitis & $6(2.2)$ & $1(0.4)$ & $7(2.6)$ \\
\hline Hypertension & $9(3.3)$ & $5(1.8)$ & $7(2.6)$ \\
\hline Cough & $5(1.8)$ & $7(2.5)$ & $7(2.6)$ \\
\hline Toothache & $1(0.4)$ & $3(1.1)$ & $6(2.2)$ \\
\hline Back pain & $10(3.7)$ & $12(4.3)$ & $5(1.9)$ \\
\hline Influenza & $6(2.2)$ & $3(1.1)$ & $5(1.9)$ \\
\hline
\end{tabular}

No clinically relevant changes from baseline in laboratory parameters or blood pressure were observed in any group. The mean changes from baseline in 12-lead ECG parameters were generally small, with no apparent treatment- or dose-related trend: two patients (placebo: $\mathrm{n}=1$; aclidinium $200 \mu \mathrm{g}: \mathrm{n}=1$ ) had a QT interval corrected for heart rate using the Fridericia formula (QTcF) of $>500 \mathrm{~ms}$, and five patients (placebo: $\mathrm{n}=2$; aclidinium $200 \mu \mathrm{g}: \mathrm{n}=3$ ) had a change in QTcF of $>60 \mathrm{~ms}$.

\section{DISCUSSION}

This study showed that, in patients with moderate to severe COPD, aclidinium $200 \mu \mathrm{g}$ or $400 \mu \mathrm{g}$ b.i.d. significantly improved lung function assessments over 24 weeks compared with placebo. The improvement in trough FEV1 with aclidinium $400 \mu \mathrm{g}$ was $128 \mathrm{~mL}$ at week 24 . Improvements in trough FEV1 with aclidinium $400 \mu \mathrm{g}$ ranged from 105 (week 12) to $140 \mathrm{~mL}$ (week 18) throughout the study, which is consistently within the proposed MCID of 100-140 mL [5, 6]. However, the improvement in trough FEV1 with aclidinium $200 \mu \mathrm{g}$ was lower, ranging from $77 \mathrm{~mL}$ (week 12) to $105 \mathrm{~mL}$ (week 18). Aclidinium $400 \mu \mathrm{g}$ also showed numerically greater improvements over the $200 \mu \mathrm{g}$ dose for FVC, inspiratory capacity and peak FEV1 values. This is one of the first bronchodilator trials to report inspiratory capacity. For both aclidinium doses, the improvement in peak FEV1 on day 1 was comparable with week 24 .

Improving health status and relieving symptoms are important goals in the management of stable COPD [2]. As the relationship between these outcomes and changes in FEV1 is poor, it is important to measure directly the effect of treatment on health status and symptoms [5]. At 24 weeks, the mean improvement with aclidinium $400 \mu \mathrm{g}$ versus placebo exceeded the MCID for SGRQ total score and equalled the MCID for TDI focal score. Such large improvements in SGRQ score are reported relatively rarely in clinical trials. With both aclidinium doses, approximately $15 \%$ more patients had an improvement that exceeded the SGRQ MCID compared with placebo. For the TDI score, $8 \%$ and $11 \%$ more patients exceeded the MCID with aclidinium $200 \mu \mathrm{g}$ and $400 \mu \mathrm{g}$, respectively, compared with placebo. These improvements are likely to translate into a noticeable benefit for patients and clinicians in routine clinical practice.

In the placebo arm, FEV1 response declined during the study, whereas SGRQ total score and TDI focal score improved. A similar lack of concordance between FEV1 and SGRQ has been observed in numerous other bronchodilator studies [12].

This study was not powered for exacerbations and the population was not enriched by recruiting patients with a history of frequent exacerbations, as reflected by the modest exacerbation rate in the placebo group. Despite the low rate of exacerbations, both aclidinium doses significantly reduced the rate of exacerbations of any severity compared with placebo. However, these results need to be confirmed in adequately powered trials. There was a similar trend in reduced rates for moderate or severe exacerbations in a second, similar, phase III study [8].

Aclidinium $200 \mu \mathrm{g}$ and $400 \mu \mathrm{g}$ b.i.d. for 24 weeks was well tolerated, with no differences between the safety profiles of the two doses. The incidence of anticholinergic adverse events in both aclidinium groups was low and similar to placebo. Moreover, no serious anticholinergic adverse events occurred in any of the study arms. The low incidence of anticholinergic adverse events reported with aclidinium is consistent with earlier studies, which showed that aclidinium is rapidly hydrolysed in human plasma into inactive metabolites $[13,14]$.

Overall, both aclidinium b.i.d. doses significantly improved bronchodilation, health status, COPD symptoms and exacerbations (any severity). The study was not powered to detect statistically significant differences between doses. However, the $400 \mu \mathrm{g}$ dose consistently demonstrated numerically greater efficacy compared with the $200 \mu \mathrm{g}$ dose and produced clinically significant improvements in lung function, health status and symptoms that were not observed with the lower dose. The 
range of improvement in trough FEV1 observed with aclidinium $400 \mu \mathrm{g}$ over the study period (105-140 mL) was comparable with results from 6- to 12-month studies of tiotropium, in which improvements ranged from 120 to $150 \mathrm{~mL}$ [15-18]. This is consistent with observations from an earlier phase II study, in which aclidinium $400 \mu \mathrm{g}$ b.i.d. produced 24-h bronchodilation that was similar to tiotropium $18 \mu \mathrm{g}$ once daily [7]. The improvement in trough FEV1 with aclidinium $400 \mu \mathrm{g}$ in the present study was also similar to that observed with the same dose in a previous 12-week, phase III study (124 $\mathrm{mL}$ at study end) [8]. The 12 -week study showed clinically significant improvements in dyspnoea with aclidinium $400 \mu \mathrm{g}$; the improvements in health status were statistically but not clinically significant, which may be because the study duration was not long enough for clinical significance to be reached. As both aclidinium doses had a similar safety profile, the risk-benefit profile appears to support aclidinium $400 \mu \mathrm{g}$ as the appropriate dose for treatment.

In conclusion, given the sustained bronchodilatory effect and low rate of anticholinergic effects, aclidinium b.i.d. may be an effective new long-acting muscarinic antagonist treatment option for patients with stable moderate or severe COPD, with the risk-benefit profile favouring the $400 \mu \mathrm{g}$ dose.

\section{SUPPORT STATEMENT}

This study was funded by Almirall, SA, Barcelona, Spain, and Forest Laboratories, Inc., NY, USA.

\section{CLINICAL TRIAL}

This study was registered with ClinicalTrials.gov with identifier NCT01001494.

\section{STATEMENT OF INTEREST}

Statements of interest for all authors, and for the study itself, can be found at www.erj.ersjournals.com/site/misc/statements.xhtml

\section{ACKNOWLEDGEMENTS}

We thank all the ATTAIN study investigators and PAREXEL International Limited. We also thank S. Gladwin from Complete Medical Communications, who provided medical writing support funded by Almirall, SA, Barcelona, Spain.

\section{REFERENCES}

1 Mannino DM, Buist AS. Global burden of COPD: risk factors, prevalence, and future trends. Lancet 2007; 370: 765-773.

2 Global Initiative for Chronic Obstructive Lung Disease. Global Strategy for Diagnosis, Management, and Prevention of COPD. www.goldcopd.com. Date last updated: 2010. Date last accessed: August 26, 2011.

3 Vestbo J, Edwards LD, Scanlon PD, et al. Changes in forced expiratory volume in 1 second over time in COPD. N Engl J Med 2011; 365: 1184-1192.

4 Jones PW, Rennard SI, Agusti A, et al. Efficacy and safety of oncedaily aclidinium in chronic obstructive pulmonary disease. Respir Res 2011; 12: 55.

5 Cazzola M, MacNee W, Martinez FJ, et al. Outcomes for COPD pharmacological trials: from lung function to biomarkers. Eur Respir J 2008; 31: 416-469.

6 Donohue JF. Minimal clinically important differences in COPD lung function. COPD 2005; 2: 111-124.

7 Fuhr R, Magnussen H, Sarem K, et al. Efficacy of aclidinium bromide $400 \mu \mathrm{g}$ twice daily compared with placebo and tiotropium in patients with moderate to severe COPD. Chest 2012; 141: 745-752.

8 Kerwin EM, D'Urzo AD, Gelb AF, et al. Efficacy and safety of a 12week treatment with twice-daily aclidinium bromide in COPD patients (ACCORD COPD I). COPD 2012; 9: 90-101.

9 Miller MR, Hankinson J, Brusasco V, et al. Standardisation of spirometry. Eur Respir J 2005; 26: 319-338.

10 Jones PW. St George's Respiratory Questionnaire: MCID. COPD 2005; 2: 75-79.

11 Mahler DA, Witek TJ Jr. The MCID of the transition dyspnea index is a total score of one unit. COPD 2005; 2: 99-103.

12 Westwood M, Bourbeau J, Jones PW, et al. Relationship between FEV1 change and patient-reported outcomes in randomised trials of inhaled bronchodilators for stable COPD: a systematic review. Respir Res 2011; 12: 40.

13 Jansat JM, Lamarca R, Garcia Gil E, et al. Safety and pharmacokinetics of single doses of aclidinium bromide, a novel long-acting, inhaled antimuscarinic, in healthy subjects. Int J Clin Pharmacol Ther 2009; 47: 460-468.

14 Sentellas S, Ramos I, Alberti J, et al. Aclidinium bromide, a new, long-acting, inhaled muscarinic antagonist: in vitro plasma inactivation and pharmacological activity of its main metabolites. Eur J Pharm Sci 2010; 39: 283-290.

15 Brusasco V, Hodder R, Miravitlles M, et al. Health outcomes following treatment for six months with once daily tiotropium compared with twice daily salmeterol in patients with COPD. Thorax 2003; 58: 399-404.

16 Casaburi R, Mahler DA, Jones PW, et al. A long-term evaluation of once-daily inhaled tiotropium in chronic obstructive pulmonary disease. Eur Respir J 2002; 19: 217-224.

17 Donohue JF, van Noord JA, Bateman ED, et al. A 6-month, placebo-controlled study comparing lung function and health status changes in COPD patients treated with tiotropium or salmeterol. Chest 2002; 122: 47-55.

18 Vincken W, van Noord JA, Greefhorst AP, et al. Improved health outcomes in patients with COPD during 1 yr's treatment with tiotropium. Eur Respir J 2002; 19: 209-216. 